\section{From sorrow to moving on... with renewed spirit}

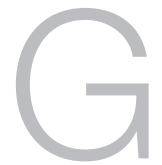
reetings to all members of the TOS community-and indeed beyond, to the degree that our efforts to reach wider audiences are successful. This issue of TOS Forum follows the publication of the memorial issue dedicated to Pierre Gy, TOS Forum no. 6. We have all experienced sorrow and reflection on the monumental life and oeuvre of Pierre Gy-but we have all also hopefully started to move on. This theme is appropriately reflected in the present issue.

This issue contains a veritable pot-pourri of features. You will find a major feature designed as a didactic overview of Gy's seminal work on chronostatistics and variographics, putting in perspective his entire 66-year scientific career. There are reports and descriptions of ongoing projects and activities of the most varied kind, spanning geographically from northern Sweden and southern Norway to Nicaragua, and content-wise ranging from a literature survey of the last 15 years on the quite specific topic "BH vs $\mathrm{RC}$-which is optimal?" via one of the more spectacular comprehensive composite sampling processes ever encountered (2000 increments, no less) and carried out entirely by hand, to particularly revealing experiences with implementing Six Sigma in the industrial complex, as complemented by variographic screening. On top of all this, the present issue starts with a real eyeopener, a draft proposal for a "Constitution of the International Pierre Gy Sampling Association (IPGSA)". Lastly, but in no way least, there is also a timely presentation of the registration brochure for the upcoming $8^{\text {th }}$ World Conference on Sampling and Blending, WCSB8. Indeed something for everybody...

Since the first organised global event (WCSB1, August 2003), our sampling community has endeavoured to move from one WCSB to the next seemingly with little trouble, organising and conducting a remarkable series of successful conferences. This is in the main due to the willingness of a succession of chairmen and their invaluable committees. However, how long can this continue? From an outside point-of-view this evolution may have looked smooth and easy, but appearances, as we know, can be deceptive. The sacrifices, toils and sweat behind any of our conferences are truly staggering. There is in reality no natural guarantee that a new willing chairman will always show up at just the right moment. And quite apart from this critical personal aspect, how do we secure a reasonable spread of locations around the world for "the next WCSB"?

Truth be told, from behind the lines, there is a danger that the world conference after next (WCSB9, 2019) may not necessarily have a place to go, and will not necessarily have a willing chairperson... (we need a female chairperson soon).

There is also another issue that has been tended to by an ad hoc and quite unofficial committee: the task of selecting the next recipient of the Pierre Gy Sampling Gold Medal (PGSGM). This has been in the hands of a non-elected committee consisting of all former award recipients, only. However, it is felt in some circles, present Editor included, that this is not sustainable in the long run, plainly because of the principal risk of scientific nepotism. I am not saying there has been any of that, or that there necessarily will be any of that in the foreseeable future, considering the upstanding gentlemen in this select group at present. But from a strict organisational point of view, it would be best to bring this very important committee under some form of elected system. At the very least to open it up to other members than only those who already carry a PGSGM around the neck.

Both the above issues have impacted on the draft proposal you will find as the opening feature in TOS Forum no. 7: a proposal for a constitution for The International Pierre Gy Sampling Association. The continued on page 19

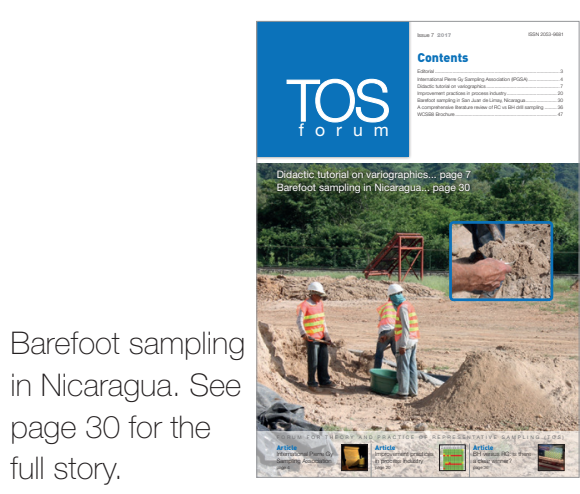

EDITOR

Kim H. Esbensen (Consultant, KHE Consulting, khe.consult@gmail.com; Adjunct Professor, Aalborg University; Adjunct

Professor, Geological Survey of Denmark and Greenland (GEUS), Copenhagen, Denmark)

PUBLISHER

lan Michael (ian@impublications.com)

C 2017 IM Publications LLP

6 Charlton Mill, Charlton, Chichester,

West Sussex PO18 OHY, UK.

Tel: +44-1243-811334;

Fax: +44-1243-811711;

E-mail: subs@impublications.com

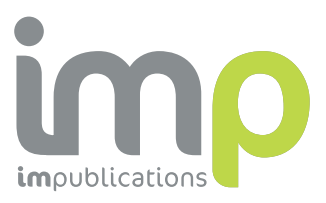

TOS forum is the communication forum for the theory and practice of representative sampling (TOS). Visit impublications.com/tos-forum for details.

Editorial correspondence to Kim Esbensen, khe.consult@gmail.com. All production correspondence should be sent to TOS forum, 6 Charlton Mill, Charlton, Chichester, West Sussex PO18 OHY, UK, Tel: +44(0)1243-811334, Fax: +44(0)1243-811711, e-mail: ian@impublications.com. 
continued from page 3

introduction further outlines the motivations of the ad hoc, pro temp committee behind the proposal. It will be vital for the future of the sampling community that all have read, contemplated and made up their minds as to this proposal, which will form the background for an inaugural assembly at WCSB8. It is important that the proposal keeps the by-laws to an absolute minimum. Check it out..

In the beginning of a year of a WCSB there will be an unavoidable hesitation to submit manuscripts to TOS Forum - there will be a quite natural wish to present contributions at our biannual conference, and to publish in the Proceedings. In spite of this the influx of features for the Forum is quite satisfactory, commensurate with two to three issues per year. Still, as always, the Editor would be remiss in his duties if he did not issue the obligatory "Call to Arms". There is a place for our biannual gatherings, the highlight of our dispersed scientific and technological community, and there is a time for similar interaction and communication between all its members in the intervening two years.
TOS Forum will be there expressly for this purpose. All communication does not necessarily have to be in the form of fully fledged scientific papers-there is a place for other contributions too. Please view the present issue of TOS Forum in this light. The Editor sincerely hopes that the efforts of the authors of the present features will be inspirational for many others. The next issue of TOS Forum is planned for September/ October 2017. Will it contain a contribution from... you? 